\title{
Flexible Environments for Hybrid Collaboration Redesigning Virtual Work Through the Four Orders of Design
}

\author{
John Meluso $^{\mathrm{a}}$, Susan Johnson ${ }^{\mathrm{b}}$, \& James Bagrow ${ }^{\mathrm{a}, \mathrm{c}}$ \\ ${ }^{a}$ Vermont Complex Systems Center, University of Vermont \\ ${ }^{\mathrm{b}}$ Weatherhead School of Management, Case Western Reserve University \\ ${ }^{c}$ Department of Mathematics \& Statistics, University of Vermont
}

June 25, 2021

\begin{abstract}
The COVID-19 pandemic made it visceral for many that virtual forms of collaborationsimultaneously liberating and frustrating — are here to stay. Workers' frustrations demonstrate that challenges remain for work designs in increasingly "hybrid" collaboration, wherein some people work face-to-face with others who work remotely. Fortunately, Buchanan's four orders of design present a framework for improving virtual forms of collaboration in conjunction with management and information systems scholarship. Here, we review the latest knowledge from these disciplines on virtual collaboration through the lens of the four orders of design. In doing so, we demonstrate that conceiving of work in terms of flexible collaborative environments could increase unity between work and workers by leveraging the capabilities of varying degrees of virtuality toward experiences that benefit all those who interact with work systems.
\end{abstract}

\section{Keywords}

virtual collaboration, information and communication technologies, COVID-19, four orders of design, future of work, team science, materiality, remote work, team virtuality, virtual teams, work from home

\section{Introduction}

Since the first industrial revolution, organizations have gathered workers together in common locations. This process, called agglomeration, ${ }^{1}$ allowed organizations to share common energy sources, tools, and goods among their employees, centralize logistics, ${ }^{2}$ and increase worker supervision and control. ${ }^{3}$ But by the 1970s, the nature of work was evolving. Expanding use of the

\footnotetext{
${ }^{1}$ W Richard Scott and Gerald F Davis, Organizations and Organizing: Rational, Natural, and Open System Perspectives, 1st ed. (Upper Saddle River, N.J.: Pearson Prentice Hall, 2007), http://www.worldcat.org/oclc/70839752.

${ }^{2}$ Nathan Rosenberg and L. E Birdzell Jr, How the West Grew Rich: The Economic Transformation of the Industrial World (Basic books, 2008).

${ }^{3}$ E. P. Thompson, “Time, Work-Discipline, and Industrial Capitalism," Past \& Present, no. 38 (1967): 56-97; Scott and Davis, Organizations and Organizing: Rational, Natural, and Open System Perspectives.
} 
telephone made "telecommuting" possible, meaning people could collaborate without physically being together. ${ }^{4}$ Tasks became "increasingly 'informated,' turning a large proportion of corporate employees at all ranks into 'knowledge workers' whose tasks are computer-mediated." The need to remain competitive drove organizations to acquire the best talent wherever those workers were located, thereby guiding collaboration toward greater "virtuality". 6

The COVID-19 pandemic conspicuously accelerated this transition, shifting $35 \%$ of US workers $^{7}$ and $80 \%$ of global corporate remote work policies ${ }^{8}$ from primarily collocated and faceto-face interactions to virtual and hybrid forms of collaboration within a few weeks. Nor was this sudden transition temporary. Nearly two-thirds (64\%) of organizations report that "remote working is a permanent change they have made due to COVID-19," with a similar fraction (69\%) reporting that at least $75 \%$ of their workforce works effectively when remote ${ }^{9}$ consistent with longheld self-assessments showing the same. ${ }^{10}$ Increasingly, individuals and organizations see the "liberating" potentials of distributed work as it grants them newfound flexibility. ${ }^{11}$

Simultaneously, millions of people struggle with "flexible" work arrangements. Even prior to the pandemic, Information \& Communication Technology (ICT) adoption frequently yielded unintended or "dual" consequences, ${ }^{12}$ an effect that more people now experience with growing hybridity. For example, while some people view Slack as a flexible lifeline amidst remote work isolation, others find its incessant notifications insufferable. ${ }^{13}$ Or you may be familiar with "Zoom fatigue." Video conferencing certainly helps people stay connected with loved ones and colleagues (in some cases the only time people saw others' faces during the pandemic), yet the experience of spending all day in video meetings often feels particularly exhausting, probably due to increased

\footnotetext{
${ }^{4}$ J. Nilles, “Telecommunications and Organizational Decentralization," IEEE Transactions on Communications 23, no. 10 (October 1975): 1142-47, https://doi.org/10.1109/TCOM.1975.1092687; Katherine M. Chudoba et al., "How Virtual Are We? Measuring Virtuality and Understanding Its Impact in a Global Organization," Information Systems Journal 15, no. 4 (2005): 279-306, https://doi.org/10.1111/j.1365-2575.2005.00200.x.

${ }^{5}$ Chudoba et al., "How Virtual Are We?"; citing Shoshana Zuboff, In the Age of the Smart Machine: The Future of Work and Power (Oxford: Heinemann Professional, 1988).

${ }^{6}$ Chudoba et al., "How Virtual Are We?"

${ }^{7}$ Erik Brynjolfsson et al., "COVID-19 and Remote Work: An Early Look at US Data” (National Bureau of Economic Research, June 15, 2020), https://doi.org/10.3386/w27344.

8 Liam Eagle, "Coronavirus Flash Survey June 2020" (S\&P Global Market Intelligence, June 2020), https://pages.marketintelligence.spglobal.com/451-on-COVID19-Request.html?utm_source=spgisite.

${ }^{9}$ Liam Eagle, “Coronavirus Flash Survey October 2020” (S\&P Global Market Intelligence, October 2020), https://pages.marketintelligence.spglobal.com/rs/565-BDO-100/images/VotE_DigitalPulse-

CoronavirusFlashSurveyOct2020-Advisory-FINAL.pdf.

${ }^{10}$ Chudoba et al., "How Virtual Are We?"

${ }^{11}$ Alexander Massey et al., "Location Liberation: Adaptive Workplaces in Government," Deloitte Insights (blog), March 4, 2021, https://www2.deloitte.com/us/en/insights/industry/public-sector/government-trends/2021/locationliberation-adaptive-workplaces-government.html.

${ }^{12}$ Ann Majchrzak, M Lynne Markus, and Jonathan Wareham, "Designing for Digital Transformation: Lessons for Information Systems Research from the Study of ICT and Societal Challenges," MIS Quarterly 40, no. 2 (June 2016): 267-77.

${ }^{13}$ Rani Molla, “Is Slack Ruining Our Jobs — and Lives?," Vox, May 1, 2019, sec. Recode, https://www.vox.com/recode/2019/5/1/18511575/productivity-slack-google-microsoft-facebook.
} 
cognitive load, self-evaluation, sensations of intimacy, and reduced mobility. ${ }^{14}$ Of course, both of these examples assume a person has sufficient or consistent enough internet access to collaborate remotely in the first place, a particularly challenging reality in many rural communities and developing nations.

Reasonably then, numerous works ${ }^{15}$ demonstrate that users "appropriate new technology by adapting it to meet their needs, which may or may not match designers' goals," even to the point where they appropriate relationships, the roles of others, and even policies. ${ }^{16}$ At some level, this process is both efficient and sufficient because users "make things work" for themselves. In fact, Leonardi et al. suggest that "tailoring systems to meet user requirements may prove impossible." Particularly as problems become increasingly complex and user populations grow "so diverse as to be incompletely definable," it may prove more effective to let those in need appropriate designs in distinct ways that work for themselves. ${ }^{17}$

That said, universal, inclusive, and feminist design advocates ${ }^{18}$ would argue (as we do) for the necessity of at least working to include everyone to mitigate inequity, an outcome most likely borne by marginalized groups. Indeed, Buchanan points out that the principle underlying approaches like design thinking and its growing appeal to organizations is "quality of experience for all those served by the organization." ${ }^{19}$ For that and other reasons, many organization scholars call for the redesign of the work systems that affect all those who work, ${ }^{20}$ the systems of interdependencies between tasks, processes, knowledge, skills, and technologies that organizations require to accomplish their goals. ${ }^{21}$ The challenges, then, of redesigning collaboration "are not

\footnotetext{
${ }^{14}$ Jeremy N. Bailenson, "Nonverbal Overload: A Theoretical Argument for the Causes of Zoom Fatigue," Technology, Mind, and Behavior 2, no. 1 (February 23, 2021), https://doi.org/10.1037/tmb0000030; Geraldine Fauville et al., "Nonverbal Mechanisms Predict Zoom Fatigue and Explain Why Women Experience Higher Levels than Men," SSRN Scholarly Paper (Rochester, NY: Social Science Research Network, April 5, 2021), https://doi.org/10.2139/ssrn.3820035.

${ }^{15}$ Paul M. Leonardi and Stephen R. Barley, "Materiality and Change: Challenges to Building Better Theory about Technology and Organizing," Information and Organization 18, no. 3 (March 10, 2008): 159-76, https://doi.org/10.1016/j.infoandorg.2008.03.001; Gerardine DeSanctis and Marshall Scott Poole, "Capturing the Complexity in Advanced Technology Use: Adaptive Structuration Theory," Organization Science 5, no. 2 (May 1994): 121-47, https://doi.org/10.1287/orsc.5.2.121; Wanda J. Orlikowski, "The Duality of Technology: Rethinking the Concept of Technology in Organizations," Organization Science 3, no. 3 (August 1, 1992): 398-427, https://doi.org/10.1287/orsc.3.3.398.

${ }^{16}$ Paul M. Leonardi et al., "Multiplex Appropriation in Complex Systems Implementation: The Case of Brazil's Correspondent Banking System," MIS Quarterly 40, no. 2 (June 2016): 462.

${ }^{17}$ Leonardi et al., 471.

${ }^{18}$ Kristin Skeide Fuglerud, "Inclusive Design of ICT: The Challenge of Diversity” (Dissertation, University of Oslo, Faculty of Humanities, 2014), https://nr.no/en/publikasjon/1183013/; Edward Steinfeld and Jordana Maisel, Universal Design: Creating Inclusive Environments (John Wiley \& Sons, 2012); P. John Clarkson et al., Inclusive Design: Design for the Whole Population (London: Springer-Verlag, 2013); Catherine D'Ignazio and Lauren F Klein, Data Feminism (MIT Press, 2020).

${ }^{19}$ Richard Buchanan, "Worlds in the Making: Design, Management, and the Reform of Organizational Culture," She Ji: The Journal of Design, Economics, and Innovation 1, no. 1 (Autumn 2015): 17, https://doi.org/10.1016/j.sheji.2015.09.003.

${ }^{20}$ Kingshuk K. Sinha and Andrew H. Van de Ven, "Designing Work within and between Organizations," Organization Science 16, no. 4 (2005): 389-408, https://doi.org/10.1287/orsc.1050.0130.

${ }^{21}$ Scott and Davis, Organizations and Organizing: Rational, Natural, and Open System Perspectives, 21.
} 
problems of action but of reaching a new understanding of the purposes and ends," 22 namely addressing the needs of all stakeholders.

Fortunately, two bodies of work hold potential to address the conundrum of hybrid collaboration. The first is Buchanan's work on the four orders of design - symbols, things, actions, and environments ${ }^{23}$ — which describes a trend long underway, moving beyond the design of objects or tools and into the design of interaction and environments. But for hybrid work specifically, the last 10 years have also seen a consolidation of knowledge by scholars of management, organizational communication, information systems, and psychology about numerous aspects of remote work, from cultural preferences for technologies to classic notions of team performance.

Hence, by reviewing the last decade of literature reviews on virtual collaboration through the lens of the four orders of design, this article proposes that designing work systems as flexible collaborative environments will increase the likelihood of producing more equitable outcomes for organizations' stakeholders. To that end, the following sections detail the four orders of design and virtual technology implementations before describing our review methodology. Then, we present the thematic outcomes of the analysis, discuss them through the lens of the four orders of design, and their implications for the future of technologies, physical and virtual workspaces, and even organizational cultures. As a result, flexible collaborative environments could leverage the benefits of varying degrees of virtuality to make work systems more satisfying for all those who interact with them.

\section{The Four Orders of Design and Their Intersections}

Uncovering the foundations of design has proven challenging, and consequently, scholars have framed its means and objectives differently over time. ${ }^{24}$ Some approach design as a science of considering "possible worlds" and selecting from among the set of alternatives, whether for objects or organizations; ${ }^{25}$ others see it as making sense of chaos by distilling simplicity from complexity; ${ }^{26}$ others still as efficient communication toward behavior modification; ${ }^{27}$ and even as a means of effecting change in the world. ${ }^{28}$ Of course, all of these are accurate in different ways and contexts, regardless of their somewhat disjointed appearance.

But part of the value of denoting the four "orders" of design is in dialectically unifying these framings. Though the names have subtly varied over time, their substances remain largely

\footnotetext{
${ }^{22}$ Richard Buchanan, "Branzi’s Dilemma: Design in Contemporary Culture,” Design Issues 14, no. 1 (Spring 1998): 16, https://doi.org/10.2307/1511825.

${ }^{23}$ Richard Buchanan, "Wicked Problems in Design Thinking," Design Issues 8, no. 2 (Spring 1992): 5-21, https://doi.org/10.2307/1511637; Richard Buchanan, "Design Research and the New Learning," Design Issues 17, no. 4 (Autumn 2001): 3-23, https://doi.org/10.1162/07479360152681056; Buchanan, "Worlds in the Making."

${ }^{24}$ Buchanan, "Wicked Problems in Design Thinking."

${ }^{25}$ Herbert A. Simon, The Sciences of the Artificial (MIT Press, 1996), 117.

${ }^{26}$ Jon Kolko, "Abductive Thinking and Sensemaking: The Drivers of Design Synthesis," Design Issues 26, no. 1 (Winter 2010): 15-28, https://doi.org/10.1162/desi.2010.26.1.15.

${ }^{27}$ Jorge Frascara, "Graphic Design: Fine Art or Social Science?," Design Issues 5, no. 1 (Autumn 1988): 18-29, https://doi.org/10.2307/1511556.

${ }^{28}$ Ilse Oosterlaken, "Design for Development: A Capability Approach," Design Issues 25, no. 4 (Autumn 2009):

91-102, https://doi.org/10.1162/desi.2009.25.4.91.
} 
the same: the first order of design involves symbols, the essence of communication. Symbols take many forms; language, images, and behaviors all convey symbolic meanings. ${ }^{29}$ But classically, this order describes disciplines like graphic design, audio, video, and communication professions. Second is the order of things or objects, whether statuary, furnishings, vehicles, electronics, software, etc. Industrial and product design certainly pervade, though so too do engineers and artists of all flavors, craftspeople, and marketers, among others. The first two orders clearly overlap in that objects often serve symbolic purposes, as with a child's favorite toy or a tote bag that advertises support for your local radio station, and potentially an identity that you seek to portray. The third order is that of action and interaction, which brings us to present notions of the design of user experiences (with technologies and other people), services, and processes. We might consider a business consultant who designs new processes (or streamlines the old). Here, too, our consultant's new process likely involves interacting with some kind of information technology on a designed device, the relevance of which would increase if the process manipulated customized manufacturing processes or, say, open office workspaces.

Which brings us to the fourth order, environments or systems. Interestingly, Buchanan further specifies that these are environments "for living, working, playing, and learning," each of which underscores the unity of purpose or thought guiding a particular environment's design. ${ }^{30}$ This order naturally lends itself to professions of built environments-architecture, urban planning, interior design - but also to professions of designed missions that draw more from the systems metaphor-systems engineering, organization design, and public policy among others. ${ }^{31}$ As with the former orders, the fourth often integrates the first three and likewise can be integrated into them, too. A public health initiative, for example, may involve the development of recognizable symbols, the construction of personal protective equipment, and the administration of vaccines, all oriented toward a unified mission of community well-being. Or serve as a symbol of worthiness for reelection. Or both, depending on the "possible world" each individual inhabits. ${ }^{32}$

Similarly, we can apply this logic to systems of virtual work. First, we need a language for discussing some attributes of virtual work.

\section{Terminology of Virtual Collaboration}

Whether our teams are collocated in the same office, distributed around the globe, or a hybrid mix of the two varying by the day, ${ }^{33}$ information and communication technologies (ICTs) play

\footnotetext{
${ }^{29}$ Eric M Eisenberg and Patricia Riley, "Organizational Culture," in The New Handbook of Organizational Communication: Advances in Theory, Research, and Methods, ed. Fredric M. Jablin and Linda L. Putnam (Thousand Oaks, CA: Sage Publications, Inc., 2001), 291-322, https://doi.org/10.4135/9781412986243.

${ }^{30}$ Buchanan, "Wicked Problems in Design Thinking," 10.

${ }^{31}$ Buchanan, "Worlds in the Making"; Buchanan, "Design Research and the New Learning."

32 The "system" metaphor makes an important contribution even as it is interchangeable with the "environment" metaphor because it allows us to move beyond a grounding in material space and into a grounding in relationships between artifacts of any kind, material or not.

${ }^{33}$ C. Marlene Fiol and Edward J. O'Connor, "Identification in Face-to-Face, Hybrid, and Pure Virtual Teams: Untangling the Contradictions," Organization Science 16, no. 1 (2005): 19-32, https://doi.org/10.1287/orsc.1040.0101.
} 
substantive roles in most present-day work designs. ICTs have significantly evolved in recent years with the additions of team chat, blogs, wikis, and more recently video calling, audio processing, computer vision, and natural language processing among many others. Technologies result in differing amounts of team virtuality, "the extent and value of utilizing information and communication technologies within work teams," 34 where value refers to the richness of the informational content provided by ICTs such as via its synchronicity or asynchronicity. Exemplary of this, integrating videoconferencing into team interactions tends to result in lower team virtuality due to its communication synchronicity and relatively rich content, as compared to email which tends toward higher asynchronicity and lower informational quality. Virtuality produces mixed results for team performance, learning, adaptation, satisfaction, trust, and identity depending on team member skills, authority structure, and how long the team has been together to name a few. ${ }^{35}$ Furthermore, the continual evolution of teams through varying configurations of remote work yields different experiences for different teams at different times.

Information systems research also examines how teams accomplish outcomes with technology through understanding the interrelated contributions of the technical artifact and the social behaviors of people. This theoretical lens, known as materiality, asserts that while users of technologies exercise some discretion over how technologies affect their work, technologies both promote and constrain certain activities based on the properties of the designed artifact $^{36}$ (here, an object shapes interaction, and perhaps interactions shape interactions). Rice and Leonardi summarize how organizations adopt, use, and benefit from ICTs. Increased adoption may arise out of "individual (e.g. innovativeness and self-efficacy), social (e.g. influence), and institutional (e.g. top management commitment) contexts.",37

Materiality may resonate with many of those who found themselves working remotely during the pandemic as specific technologies, their implementations, and social uses often shape such experiences - for better and worse. In general, a team or organization's network may expand from ICT use, as with professional social media sites, though information overload can dampen the benefits of this outcome. As in the pandemic, the flexibility of "working from anywhere" juxtaposes challenges that may result from disruption of organizational structures, work processes, differences in geography, culture, professionalism, and interaction frequency. Readers can likely recall similar instances in their own careers.

Such mixed experiences bring us back to Buchanan. Our current work systems do yield outcomes of both individual and collective good; neither individuals nor organizations would hail

\footnotetext{
${ }^{34}$ John M Schaubroeck and Andrew Yu, "When Does Virtuality Help or Hinder Teams? Core Team Characteristics as Contingency Factors," Human Resource Management Review 27, no. 4 (December 2017): 636, https://doi.org/10.1016/j.hrmr.2016.12.009.

35 Chudoba et al., "How Virtual Are We?"; Mei Lu et al., "Virtuality and Team Performance: Understanding the Impact of Variety of Practices," Journal of Global Information Technology Management 9, no. 1 (2006): 4-23, https://doi.org/10.1080/1097198X.2006.10856412; Schaubroeck and Yu, "When Does Virtuality Help or Hinder Teams? Core Team Characteristics as Contingency Factors."

${ }^{36}$ Ronald E Rice and Paul M Leonardi, "Information and Communication Technologies in Organizations," The SAGE Handbook of Organizational Communication: Advances in Theory, Research, and Methods, 2014, 425-48.

${ }^{37}$ Rice and Leonardi, 430.
} 
their benefits otherwise! And still, "if the purpose of design thinking is to create the environments within which we live [and work], the purpose is also to make possible the unity of the individual with the environments that human beings create." Whether caused by "practical," "intellectual," or "emotional" dissatisfaction, "the felt unity of an experience is broken, trust and confidence are diminished, and human satisfaction in the fulfillment of reaching a goal is lost." 38

Therefore, work as we know it only partially "works." To understand why, the remainder of this piece reviews the established knowledge on virtual collaboration through the four orders. As we will see, hybrid work systems need to accommodate individuals and teams alike, flexibly and simultaneously to fully facilitate unity. But, in doing so, they may also create opportunities not currently afforded to existing work systems.

\section{Review Methodology}

For this work, we conducted a "review of reviews," known in the information systems literature as an umbrella review or an overview of reviews, following the procedure outlined in Templier \& Paré. ${ }^{39}$ We searched all 41 databases included in ABI/INFORM on ProQuest for reviews that describe accepted knowledge about virtual work. We did this by searching for explicit review articles, meaning the work self-identified as a review or meta-analysis of virtual, hybrid, distributed, or remote aspects of work, collaboration, teams, or groups. ${ }^{40}$

We screened for article quality by performing this search within the Association of Information Systems' "basket of eight" journals (European Journal of Information Systems, Information Systems Journal, Information Systems Research, Journal of AIS, Journal of Information Technology, Journal of MIS, Journal of Strategic Information Systems, and MIS Quarterly) in addition to eight top Management journals (Academy of Management Review, Academy of Management Journal, Organization Science, Management Science, Organizational Behavior and Human Decision Processes, Administrative Science Quarterly, Human Resource Management Review, and Journal of Management) and two relevant Organizational Psychology journals (Journal of Applied Psychology and Small Group Research). We also limited the search to the years 2010-2020 to ensure our findings represented the most up-to-date knowledge from the field while allowing time for studies of different perspectives to accrue. Collectively, these returned 30 unique articles. We then excluded articles which did not self-identify as reviews or meta-analyses (for example, Human Resource Management Review yielded several false positives due to the journal name) or reviewed an adjacent topic ${ }^{41}$ leaving 13 studies (see Table 1), eight of which hailed from a Human Resources Management Review special issue on virtual teams from

\footnotetext{
38 Buchanan, "Worlds in the Making," 19.

${ }^{39}$ Mathieu Templier and Guy Paré, "A Framework for Guiding and Evaluating Literature Reviews," Communications of the Association for Information Systems 37, no. 1 (August 2015), https://doi.org/10.17705/1CAIS.03706.

40 The logical expression for this search is "noft(virtual OR hybrid OR distributed OR remote) AND noft(work OR collaboration OR teams OR groups) AND noft(review)" where "noft" means no full text.

${ }^{41}$ Specifically Stefan Jooss, Anthony McDonnell, and Kieran Conroy, "Flexible Global Working Arrangements: An Integrative Review and Future Research Agenda," Human Resource Management Review, August 27, 2020, 100780, https://doi.org/10.1016/j.hrmr.2020.100780 which deals with location rather than virtuality.
} 
2017. Lastly, given our interest in the design of hybrid work arrangements, we limited our review to findings within virtual professional contexts by excluding any findings from purely collocated settings. ${ }^{42}$

Within the 13 studies, then, we recorded the theme identified by the authors; associated the factors of each finding as inputs, moderators, mediators, or outputs; noted its association with individuals, leaders, teams, or organizations; and the relationship between factors as positivelyrelated, negatively-related, having mixed effects, or no effect. Many of the inductive thematic reviews cited findings with only one study supporting the finding, so only findings with multiple supporting studies were included to ensure claim validation. For instances in which the object of study was not specified, the party enacting or affected by a given practice was inferred from context. Furthermore, statements about generic "effects" were designated as having "mixed effects" on a generic "outcomes" specification. Following the compilation of these findings, we inductively coded the findings identified within each study, partially informed by the authoridentified thematic categories. As will quickly become apparent, a significant majority of the findings involve preferences and attributes that we might classify as third-order and fourth-order, but also involving nearly ubiquitous variation.

\footnotetext{
${ }^{42}$ Several articles distinguish between professional- and student-derived knowledge (e.g. Jennifer L Gibbs, Anu Sivunen, and Maggie Boyraz, "Investigating the Impacts of Team Type and Design on Virtual Team Processes," Human Resource Management Review 27, no. 4 (December 2017): 590-603, https://doi.org/10.1016/j.hrmr.2016.12.006.).
} 


\begin{tabular}{|c|c|c|c|c|c|}
\hline Authors & Year & Review Title & Publication & Review Type & Terminology \\
\hline $\begin{array}{l}\text { Breuer, Christina; } \\
\text { Hüffmeier, Joachim; } \\
\text { Hertel, Guido }\end{array}$ & 2016 & $\begin{array}{l}\text { Does trust matter more in } \\
\text { virtual teams? A meta- } \\
\text { analysis of trust and team } \\
\text { effectiveness considering } \\
\text { virtuality and } \\
\text { documentation as } \\
\text { moderators }\end{array}$ & $\begin{array}{l}\text { Journal of } \\
\text { Applied } \\
\text { Psychology }\end{array}$ & Meta-analysis & Virtual teams \\
\hline $\begin{array}{l}\text { Gibbs, Jennifer L.; } \\
\text { Sivunen, Anu; } \\
\text { Boyraz, Maggie }\end{array}$ & 2017 & $\begin{array}{l}\text { Investigating the impacts of } \\
\text { team type and design on } \\
\text { virtual team processes }\end{array}$ & $\begin{array}{l}\text { Human } \\
\text { Resource } \\
\text { Management } \\
\text { Review }\end{array}$ & $\begin{array}{l}\text { Thematic } \\
\text { inductive }\end{array}$ & Virtual teams \\
\hline $\begin{array}{l}\text { Gilson, Lucy L.; } \\
\text { Maynard, M. Travis; } \\
\text { Young, Nicole C. } \\
\text { Jones; Vartiainen, } \\
\text { Matti; Hakonen, } \\
\text { Marko }\end{array}$ & 2015 & $\begin{array}{l}\text { Virtual teams research: } 10 \\
\text { years, } 10 \text { themes, and } 10 \\
\text { opportunities }\end{array}$ & $\begin{array}{l}\text { Journal of } \\
\text { Management }\end{array}$ & $\begin{array}{l}\text { Thematic } \\
\text { inductive }\end{array}$ & Virtual teams \\
\hline $\begin{array}{l}\text { Han, Soo Jeoung; } \\
\text { Beyerlein, Michael }\end{array}$ & 2016 & $\begin{array}{l}\text { Framing the effects of } \\
\text { multinational cultural } \\
\text { diversity on virtual team } \\
\text { processes }\end{array}$ & $\begin{array}{l}\text { Small Group } \\
\text { Research }\end{array}$ & $\begin{array}{l}\text { Thematic } \\
\text { inductive }\end{array}$ & $\begin{array}{l}\text { Multinational } \\
\text { virtual teams }\end{array}$ \\
\hline $\begin{array}{l}\text { Handke, Lisa; } \\
\text { Klonek, Florian E.; } \\
\text { Parker, Sharon K.; } \\
\text { Kauffeld, Simone }\end{array}$ & 2020 & $\begin{array}{l}\text { Interactive effects of team } \\
\text { virtuality and work design } \\
\text { on team functioning }\end{array}$ & $\begin{array}{l}\text { Small Group } \\
\text { Research }\end{array}$ & $\begin{array}{l}\text { Thematic } \\
\text { inductive }\end{array}$ & Virtual teams \\
\hline $\begin{array}{l}\text { Hoch, Julia E.; } \\
\text { Dulebohn, James H. }\end{array}$ & 2017 & $\begin{array}{l}\text { Team personality } \\
\text { composition, emergent } \\
\text { leadership and shared } \\
\text { leadership in virtual teams: } \\
\text { A theoretical framework }\end{array}$ & $\begin{array}{l}\text { Human } \\
\text { Resource } \\
\text { Management } \\
\text { Review }\end{array}$ & $\begin{array}{l}\text { Thematic } \\
\text { inductive }\end{array}$ & Virtual teams \\
\hline $\begin{array}{l}\text { Kramer, William S.; } \\
\text { Shuffler, Marissa L.; } \\
\text { Feitosa, Jennifer }\end{array}$ & 2017 & $\begin{array}{l}\text { The world is not flat: } \\
\text { Examining the interactive } \\
\text { multidimensionality of } \\
\text { culture and virtuality in } \\
\text { teams }\end{array}$ & $\begin{array}{l}\text { Human } \\
\text { Resource } \\
\text { Management } \\
\text { Review }\end{array}$ & $\begin{array}{l}\text { Thematic } \\
\text { inductive }\end{array}$ & Virtual teams \\
\hline Liao, Chenwei & 2017 & $\begin{array}{l}\text { Leadership in virtual teams: } \\
\text { A multilevel perspective }\end{array}$ & $\begin{array}{l}\text { Human } \\
\text { Resource } \\
\text { Management } \\
\text { Review }\end{array}$ & $\begin{array}{l}\text { Thematic } \\
\text { inductive }\end{array}$ & Virtual teams \\
\hline $\begin{array}{l}\text { Marlow, Shannon } \\
\text { L.; Lacerenza, } \\
\text { Christina N.; Salas, } \\
\text { Eduardo }\end{array}$ & 2017 & $\begin{array}{l}\text { Communication in virtual } \\
\text { teams: A conceptual } \\
\text { framework and research } \\
\text { agenda }\end{array}$ & $\begin{array}{l}\text { Human } \\
\text { Resource } \\
\text { Management } \\
\text { Review }\end{array}$ & $\begin{array}{l}\text { Thematic } \\
\text { inductive }\end{array}$ & Virtual teams \\
\hline
\end{tabular}




\begin{tabular}{|c|c|c|c|c|c|}
\hline Authors & Year & Review Title & Publication & Review Type & Terminology \\
\hline $\begin{array}{l}\text { Mesmer-Magnus, } \\
\text { Jessica R.; } \\
\text { DeChurch, Leslie } \\
\text { A.; Jimenez- } \\
\text { Rodriguez, Miliani; } \\
\text { Wildman, Jessica; } \\
\text { Shuffler, Marissa }\end{array}$ & 2011 & $\begin{array}{l}\text { A meta-analytic } \\
\text { investigation of virtuality } \\
\text { and information sharing in } \\
\text { teams }\end{array}$ & $\begin{array}{l}\text { Organizational } \\
\text { Behavior and } \\
\text { Human } \\
\text { Decision } \\
\text { Processes }\end{array}$ & Meta-analysis & Virtual teams \\
\hline Roehling, Mark & 2017 & $\begin{array}{l}\text { The important but } \\
\text { neglected legal context of } \\
\text { virtual teams: Research } \\
\text { implications and } \\
\text { opportunities }\end{array}$ & $\begin{array}{l}\text { Human } \\
\text { Resource } \\
\text { Management } \\
\text { Review }\end{array}$ & $\begin{array}{l}\text { Thematic } \\
\text { inductive }\end{array}$ & Virtual teams \\
\hline $\begin{array}{l}\text { Schaubroeck, John } \\
\text { M.; Yu, Andrew }\end{array}$ & 2017 & $\begin{array}{l}\text { When does virtuality help } \\
\text { or hinder teams? Core team } \\
\text { characteristics as } \\
\text { contingency factors }\end{array}$ & $\begin{array}{l}\text { Human } \\
\text { Resource } \\
\text { Management } \\
\text { Review }\end{array}$ & $\begin{array}{l}\text { Thematic } \\
\text { inductive }\end{array}$ & Virtual teams \\
\hline $\begin{array}{l}\text { Schmidtke, James } \\
\text { M.; Cummings, } \\
\text { Anne }\end{array}$ & 2017 & $\begin{array}{l}\text { The effects of virtualness } \\
\text { on teamwork behavioral } \\
\text { components: The role of } \\
\text { shared mental models }\end{array}$ & $\begin{array}{l}\text { Human } \\
\text { Resource } \\
\text { Management } \\
\text { Review }\end{array}$ & $\begin{array}{l}\text { Thematic } \\
\text { inductive }\end{array}$ & Virtual teams \\
\hline
\end{tabular}

Table 1: The 13 review articles included in the umbrella review. Included are the authors, years of publication, review titles, publication titles, the type of reviews (either thematic inductive or meta-analytic), and the terminology identified by the search criteria. Articles are presented in alphabetical order by lead author.

\section{Results: Hybrid Collaborations as Environments}

Following the procedure described in the previous section, we identified a total of 243 claims made across the reviews that satisfied the specified criteria. An inductive coding process distilled these findings into 14 themes which we gathered into four categories, summarized in Table 2 with the number of articles and the total number of claims displayed for each category and theme. Of course, many of these claims are redundant with one another because different reviews frequently refer to the same articles; hence, these quantities metaphorically represent the relative attention paid to each topic (within and across disciplines) and the abundance of nuance within each category rather than the importance of each. Also, themes can and do apply to multiple categories, but we chose an organization into personality traits, task expectations, task resources, and team interaction for how the sequence both parallels the progression of a project and the categories' demonstration of the orders.

The findings of these studies are too numerous to recount here in full. Instead, we briefly summarize the claims that fall within each category and theme to contextualize their subsequent consideration through the four orders. 


\begin{tabular}{|c|c|c|c|c|c|c|c|c|}
\hline \multirow[t]{2}{*}{ Category } & \multirow{2}{*}{$\begin{array}{l}\text { Inductive } \\
\text { Theme }\end{array}$} & \multirow{2}{*}{$\begin{array}{c}\text { Num. } \\
\text { Reviews } \\
\text { Appears } \\
\text { In }\end{array}$} & \multirow{2}{*}{$\begin{array}{l}\text { Num. } \\
\text { Claims }\end{array}$} & \multicolumn{5}{|c|}{ Relationship } \\
\hline & & & & Positive & Negative & $\begin{array}{c}\text { No } \\
\text { Effect }\end{array}$ & $\begin{array}{l}\text { Mixed } \\
\text { Effects }\end{array}$ & Mediates \\
\hline $\begin{array}{l}\text { Personality } \\
\text { Traits }\end{array}$ & $\begin{array}{l}\text { Personality } \\
\text { Traits }\end{array}$ & 1 & 25 & $80.0 \%$ & & & $12.0 \%$ & $8.0 \%$ \\
\hline \multicolumn{2}{|c|}{ Personality Traits Total } & 1 & 25 & $\mathbf{8 0 . 0 \%}$ & & & $12.0 \%$ & $8.0 \%$ \\
\hline \multirow{2}{*}{$\begin{array}{l}\text { Task } \\
\text { Expectations }\end{array}$} & Job Demands & 2 & 8 & $25.0 \%$ & $37.5 \%$ & & $37.5 \%$ & \\
\hline & $\begin{array}{l}\text { Legal } \\
\text { Frameworks }\end{array}$ & 1 & 8 & & & & $100.0 \%$ & \\
\hline \multicolumn{2}{|c|}{ Task Expectations Total } & 3 & 16 & $12.5 \%$ & $18.8 \%$ & & $68.8 \%$ & \\
\hline \multirow{3}{*}{$\begin{array}{l}\text { Task } \\
\text { Resources }\end{array}$} & Information & 2 & 4 & $50.0 \%$ & $25.0 \%$ & & $25.0 \%$ & \\
\hline & Technology & 3 & 7 & $14.3 \%$ & $14.3 \%$ & & $71.4 \%$ & \\
\hline & Virtuality & 1 & 6 & $50.0 \%$ & $50.0 \%$ & & & \\
\hline \multicolumn{2}{|c|}{ Task Resources Total } & 4 & 17 & $35.3 \%$ & $29.4 \%$ & & $35.3 \%$ & \\
\hline \multirow{8}{*}{$\begin{array}{l}\text { Team } \\
\text { Interaction }\end{array}$} & Communication & 5 & 50 & $50.0 \%$ & $32.0 \%$ & & & $18.0 \%$ \\
\hline & Conflict & 1 & 2 & $50.0 \%$ & & & $50.0 \%$ & \\
\hline & Culture & 6 & 67 & $70.1 \%$ & $17.9 \%$ & $1.5 \%$ & $7.5 \%$ & $3.0 \%$ \\
\hline & Leadership & 5 & 34 & $52.9 \%$ & $2.9 \%$ & & & $44.1 \%$ \\
\hline & $\begin{array}{l}\text { Task } \\
\text { Interdependence }\end{array}$ & 1 & 7 & $71.4 \%$ & $14.3 \%$ & & $14.3 \%$ & \\
\hline & Team Building & 1 & 4 & $50.0 \%$ & & & $50.0 \%$ & \\
\hline & Team Cognition & 1 & 11 & $36.4 \%$ & $54.5 \%$ & & & $9.1 \%$ \\
\hline & Trust & 4 & 10 & $70.0 \%$ & $10.0 \%$ & & $10.0 \%$ & $10.0 \%$ \\
\hline \multicolumn{2}{|c|}{ Team Interaction Total } & 13 & 185 & $58.9 \%$ & $20.0 \%$ & $0.5 \%$ & $5.4 \%$ & $15.1 \%$ \\
\hline \multicolumn{2}{|l|}{ Grand Total } & 13 & 243 & $56.4 \%$ & $18.5 \%$ & $0.4 \%$ & $12.3 \%$ & $12.3 \%$ \\
\hline
\end{tabular}

Table 2: A statistical summary of the claims identified in the review articles. The claims are presented by category and inductive theme, including the number of review articles in which each category and theme appeared. Then, the relationships between the factors composing each claim are described in terms of the percentage of claims in which the factors were positively related, negatively related, in which there were no effects, mixed effects, and in which a factor was identified as mediating two other factors. 


\section{Personality Traits \& Virtuality}

Projects often start by constructing teams. A review by Hoch $\&$ Dulebohn ${ }^{43}$ provides, to the best of our knowledge, a unique synthesis of organizational psychology literature describing the relationships between the "big five" personality dimensions (extraversion, agreeableness, conscientiousness, openness, and emotional stability) and leadership in virtual teams.

With respect to individuals, all five traits correlate with increased likelihood of that person emerging as a leader, and individual leadership emergence correlates with team performance. With respect to team composition, relationships become more mixed. Several qualities (conscientiousness, agreeableness, emotional stability) are positively correlated with shared leadership and team performance, while others (extraversion and openness) have mixed effects on both shared leadership and team performance. Increasing virtuality is positively related to the likelihood that leadership will emerge and that the team will share leadership in all but cases wherein the team scores highly on agreeableness, which tends more toward shared leadership.

Returning to team design, a manager might approach the formation of a team with a unifying thought of how to pursue a goal. We can assume managers and organizations may have some control over the personality composition of their teams contingent on other constraints, but only some control. People have unique identities with varying degrees of each quality, if people are even reducible in five traits, so we cannot assume that every manager (or any manager) can form "optimal" team compositions. Nevertheless, the result of forming a team is designing a human system, an environment of interacting identities, ${ }^{44}$ with unique values and interests, embodied in the people we work with toward goal-attainment.

\section{Task Expectations}

Gradually, teams construct explicit and tacit expectations. ${ }^{45}$ In virtual teams, those expectations can include anything from roles and responsibilities, to social norms, to government regulations. The several reviews that discuss this topic ${ }^{46}$ tend to describe what we might call incentives or job demands and how those limitations and subsequent rewards shape outcomes. The majority of the findings relate to teams, but also to individual well-being and organizational outcomes.

Beginning with individuals, constraints on one's job (e.g. time, role ambiguity) tend to somewhat decrease functioning, but yield mixed effects depending on the kind of constraint

\footnotetext{
43 Julia E Hoch and James H Dulebohn, "Team Personality Composition, Emergent Leadership and Shared Leadership in Virtual Teams: A Theoretical Framework," Human Resource Management Review 27, no. 4 (December 2017): 678-93, https://doi.org/10.1016/j.hrmr.2016.12.012.

${ }^{44}$ Fiol and O'Connor, "Identification in Face-to-Face, Hybrid, and Pure Virtual Teams."

${ }^{45}$ Gilad Chen and Richard J. Klimoski, "The Impact of Expectations on Newcomer Performance in Teams as Mediated by Work Characteristics, Social Exchanges, and Empowerment," Academy of Management Journal 46, no. 5 (October 1, 2003): 591-607, https://doi.org/10.5465/30040651.

${ }^{46}$ Lisa Handke et al., "Interactive Effects of Team Virtuality and Work Design on Team Functioning," Small Group Research 51, no. 1 (February 1, 2020): 3-47, https://doi.org/10.1177/1046496419863490; Lucy L Gilson et al., "Virtual Teams Research: 10 Years, 10 Themes, and 10 Opportunities," Journal of Management 41, no. 5 (July 2015): 1313-37, https://doi.org/10.1177/0149206314559946; Mark Roehling, "The Important but Neglected Legal Context of Virtual Teams: Research Implications and Opportunities," Human Resource Management Review, Virtual Teams in Organizations, 27, no. 4 (December 2017): 621-34, https://doi.org/10.1016/j.hrmr.2016.12.008.
} 
(virtually is more constraining with short-term projects than long, for example). Likewise mixed effects exist with respect to well-being and varying amounts of virtuality. ${ }^{47}$ In terms of team constructs such as task non-routineness and rewards, mixed-incentives (that is, rewards at both the individual and group levels) are positively related to individual well-being while improving team performance. ${ }^{48}$ Problem-solving demands (like difficulty) yield mixed results for performance, additionally so when moderated by virtuality, though both decrease performance and trust on average. Perhaps surprising to some, how unique or non-routine a task is can decrease trust in a team. $^{49}$

Legal frameworks increasingly prove relevant as teams become more global, often resulting in uncertainty for virtual teams because of the relative recency of virtual collaboration compared to legal timescales. ${ }^{50}$ COVID-19 brought this issue to the fore as workers who previously commuted across borders began working full time in different tax jurisdictions. National and transnational laws shape labor standards, safety, compensation, freedom from discrimination, etc. Organizations also establish "private law" that can affect workers' rights and obligations, such as through contracts and adoption of international standards, thereby raising questions of legal statuses of virtual and hybrid employees and employers depending on the borders one crosses. Thus far, "countries have not significantly adapted their approach to determining the legal status of a [hybrid] worker as an employee" resulting in "significant ambiguity." 51

Returning to the orders, think of incentives as objects to achieve or avoid that shape the processes (actions and interactions) that individuals and teams design toward goal-attainment, even as they can also serve symbolic purposes for organizations. Likewise, legal constructs serve symbolic, objective, and procedural purposes. How effectively those objects of achievement draw in, and those objects of avoidance deter, will depend on the alignment between the incentive environments of teams, ${ }^{52}$ but also of individuals, organizations, and governments among environments both internal and external to a team.

\section{Task Resources}

Teams draw on resources to perform tasks and achieve their goals. Resources are "aspects of the job that help achieve work goals, reduce demands, or promote growth from the job demandsresources model of work design." 53 So while materials qualify, so too will teams make use of information, social networks, skills, tools, etc.

Perhaps the most (superficially) intuitive resource in virtual work is technology. Harking back to materiality, different technologies have different effects on both individual and team

\footnotetext{
${ }^{47}$ Handke et al., "Interactive Effects of Team Virtuality and Work Design on Team Functioning."

${ }^{48}$ Gilson et al., "Virtual Teams Research: 10 Years, 10 Themes, and 10 Opportunities."

${ }^{49}$ Handke et al., "Interactive Effects of Team Virtuality and Work Design on Team Functioning."

${ }^{50}$ Roehling, "The Important but Neglected Legal Context of Virtual Teams."

${ }^{51}$ Roehling, 625.

52 These incentive environments might rhyme with utility functions from game theory or constraint functions in optimization.

${ }^{53}$ Handke et al., "Interactive Effects of Team Virtuality and Work Design on Team Functioning," 12.
} 
outcomes, further depending on the context in which the tool is used and the user's experience with the tool, though organizations can sometimes supplement experience with training. ${ }^{54}$ Specifically referring to ICTs, those technologies are related to numerous individual-level outcomes including some improvements (reduced social loafing, increased perceptions of leader competence and satisfaction) and some degradations (decreased perceptions of productivity, decreased extrarole activity, and increased decision time), ${ }^{55}$ though again to varying extents among many other instances of virtuality moderation.

Information, too, plays important roles albeit with various effects; having access to more information can produce positive or negative outcomes, though certain kinds, like feedback about processes and outcomes, tend to correlate with improved team functioning ${ }^{56}$ while others, say a person's knowledge sharing abilities, correlate with decreased social network development. ${ }^{57}$

Combined, even resources tell increasingly nuanced tales through concepts like materiality. The choices involved in constructing a team's virtuality extend beyond the second-order, they predicate team processes through which people exchange information in a web of exchanges that leave us with a combined virtual-material, informated environment encompassing all of our genres of communication in hybrid configurations along with the tools of knowledge work. One major resource is obviously missing here: "the team" also serves as a resource. We consider its myriad interactions next.

\section{Team Interaction}

Teams play such important roles in current work designs that we practically take their existences for granted. Unequivocally, they are incredibly complex ${ }^{58}$ Our review identified eight themes that naturally coalesce within virtual team interaction: communication, conflict, culture, leadership, task interdependence, team building, team cognition, and trust. We address three themes here briefly because in most cases, each theme is laden with a mix of positive and negative relationships, mediators, and moderators as demonstrated by the relationship fractions shown in Table 2 .

The research on communication describes relationships between individual- and teamlevel inputs (e.g. frequency, timeliness, virtuality, skill level), through numerous mediators (e.g. uniqueness, openness, privacy, temporal stability, authority, virtuality), to individual- and teamlevel outputs (e.g. performance, trust, satisfaction, innovation, identity), and moderated by other constructs (e.g. virtuality, task complexity, skill). ${ }^{59}$ Of the relationships, 50\% identify positive

\footnotetext{
${ }^{54}$ Gibbs, Sivunen, and Boyraz, "Investigating the Impacts of Team Type and Design on Virtual Team Processes"; Soo Jeoung Han and Michael Beyerlein, "Framing the Effects of Multinational Cultural Diversity on Virtual Team Processes," Small Group Research 47, no. 4 (August 1, 2016): 351-83, https://doi.org/10.1177/1046496416653480; Gilson et al., "Virtual Teams Research: 10 Years, 10 Themes, and 10 Opportunities."

${ }^{55}$ Gilson et al., "Virtual Teams Research: 10 Years, 10 Themes, and 10 Opportunities."

${ }^{56}$ Handke et al., "Interactive Effects of Team Virtuality and Work Design on Team Functioning."

${ }^{57}$ Han and Beyerlein, "Framing the Effects of Multinational Cultural Diversity on Virtual Team Processes."

${ }^{58}$ Holly Arrow, Joseph McGrath, and Jennifer Berdahl, Small Groups as Complex Systems: Formation, Coordination, Development, and Adaptation (Thousand Oaks, California, 2000), https://doi.org/10.4135/9781452204666.

${ }^{59}$ Han and Beyerlein, "Framing the Effects of Multinational Cultural Diversity on Virtual Team Processes"; Shannon L Marlow, Christina N Lacerenza, and Eduardo Salas, "Communication in Virtual Teams: A Conceptual
} 
relationships between the input and output, 32\% negative, and $18 \%$ mediate relationships reinforcing the significant nuance.

Next, much of the culture research considers diversity based on geographic dispersion or national origin. ${ }^{60}$ Kramer et al. conduct another unique review of cultural typologies including Hofstede's cultural dimensions, Triandis' cultural typology, Trompenaars' cultural differences, high-low context cultures, and tight vs. loose cultures. ${ }^{61}$ Several also consider topics of subgroup formation, language barriers, and workplace harassment. ${ }^{62}$ Each of these cultures are then related to greatly varied outcomes including more pervasive constructs (e.g. team performance) but more often culture-relevant outcomes (e.g. team identification, tool preference by culture, coordination difficulty, subgroup formation, conflict). Here, $70 \%$ of the findings describe positive relationships between the input and output, $18 \%$ negative, and $8 \%$ mixed effects. Many of the positive items describe cultural preferences for high or low tool synchronicity, compliance with authority's choices, and reliance on virtual tools. Collectively, these again demonstrate that a "one size fits all" work design is unlikely to prove fruitful.

Finally, we consider trust, one of the most widely studied topics in virtual teams which has consistently resulted in mixed findings. ${ }^{63}$ Initially, many of the findings seem intuitive: team trust is positively correlated with performance and likewise between individual trust and increased communication. But particular communicative behaviors reveal mixed relations to team trust, again adding nuance even as qualities like building trust early, positive tone, and knowledge sharing are positively related to building "swift trust" in shorter-term teams.

To repeat, these samples from communication, culture, and trust merely provide a subset of the complexity imbuing team interaction. Concurrently, they call into question the notion of a singular design as team environments-human systems of interaction-necessarily involve

\footnotetext{
Framework and Research Agenda," Human Resource Management Review 27, no. 4 (December 2017): 575-89, https://doi.org/10.1016/j.hrmr.2016.12.005; Jessica R. Mesmer-Magnus and Leslie A. DeChurch, "Information Sharing and Team Performance: A Meta-Analysis," Journal of Applied Psychology 94, no. 2 (2009): 535-46, https://doi.org/10.1037/a0013773; Roehling, “The Important but Neglected Legal Context of Virtual Teams"; Schaubroeck and $\mathrm{Yu}$, "When Does Virtuality Help or Hinder Teams? Core Team Characteristics as Contingency Factors."

${ }^{60}$ Gibbs, Sivunen, and Boyraz, "Investigating the Impacts of Team Type and Design on Virtual Team Processes"; Gilson et al., "Virtual Teams Research: 10 Years, 10 Themes, and 10 Opportunities"; Han and Beyerlein, "Framing the Effects of Multinational Cultural Diversity on Virtual Team Processes."

${ }^{61}$ William S. Kramer, Marissa L. Shuffler, and Jennifer Feitosa, "The World Is Not Flat: Examining the Interactive Multidimensionality of Culture and Virtuality in Teams," Human Resource Management Review, Virtual Teams in Organizations, 27, no. 4 (December 2017): 604-20, https://doi.org/10.1016/j.hrmr.2016.12.007.

${ }^{62}$ Gibbs, Sivunen, and Boyraz, "Investigating the Impacts of Team Type and Design on Virtual Team Processes"; Gilson et al., "Virtual Teams Research: 10 Years, 10 Themes, and 10 Opportunities"; Roehling, "The Important but Neglected Legal Context of Virtual Teams."

${ }^{63}$ Christina Breuer, Joachim Hüffmeier, and Guido Hertel, "Does Trust Matter More in Virtual Teams? A MetaAnalysis of Trust and Team Effectiveness Considering Virtuality and Documentation as Moderators," Journal of Applied Psychology 101, no. 8 (2016): 1151-77, https://doi.org/10.1037/ap10000113; Gilson et al., "Virtual Teams Research: 10 Years, 10 Themes, and 10 Opportunities"; Han and Beyerlein, "Framing the Effects of Multinational Cultural Diversity on Virtual Team Processes"; Roehling, "The Important but Neglected Legal Context of Virtual Teams."
} 
heterogeneous identities, incentives, and information. Next, we address the challenge of advancing toward work systems that achieve unity between their environments.

\section{Discussion}

Multiple systems of work artifacts underlie virtual collaboration. Our understanding of work systems grows more complex as we frame environments of identities, incentives, information, and others as interacting, "nested within another and another, stretching all of the way from the goods and services provided to the customer to the top of organizational leadership," as Buchanan similarly remarks about organizational culture. ${ }^{64}$ Organizational culture is a socially-constructed environment; in this work, we have described hybrid collaboration as overlapping sociotechnical, co-constructed environments, collectively forming a hybrid work environment in which humans shape humans, shape technology, shape humans.

Work environments cannot be static, singular constructs if we seek to achieve unity between heterogeneous stakeholders. That said, adopting plural designs would expect minorities of all kinds to assimilate into dominant norms and likely will not create unity either. Instead, according to Nishii, "the key to moving from a plural organization to an inclusive one is to alter the sociorelational context[, the environment] within which heterogeneous individuals interact." So we must strive for work systems that are flexible enough to facilitate personalization, ${ }^{65}$ purposively designing in ways for workers to "appropriate" work designs, if you will. This reorientation is a logical outgrowth of various research streams on structural flexibility, ${ }^{66}$ digital innovation, ${ }^{67}$ flexible technologies ${ }^{68}$ and organization design ${ }^{69}$ among others. ${ }^{70}$ Therefore, we

\footnotetext{
${ }^{64}$ Buchanan, "Worlds in the Making," 20.

${ }^{65}$ Lisa H. Nishii, "The Benefits of Climate for Inclusion for Gender-Diverse Groups," Academy of Management Journal 56, no. 6 (October 9, 2012): 1754, https://doi.org/10.5465/amj.2009.0823.

${ }^{66}$ Seyed M. Iravani, Mark P. Van Oyen, and Katharine T. Sims, "Structural Flexibility: A New Perspective on the Design of Manufacturing and Service Operations," Management Science 51, no. 2 (February 2005): 151-66, https://doi.org/10.1287/mnsc.1040.0333.

${ }^{67}$ Rajiv Kohli and Nigel P. Melville, "Digital Innovation: A Review and Synthesis," Information Systems Journal 29, no. 1 (January 2019): 200-223, https://doi.org/10.1111/isj.12193.

${ }^{68}$ Paul M. Leonardi, "When Flexible Routines Meet Flexible Technologies: Affordance, Constraint, and the Imbrication of Human and Material Agencies," MIS Quarterly 35, no. 1 (March 2011): 147-67, https://doi.org/10.2307/23043493.

${ }^{69}$ Saras D. Sarasvathy et al., "Designing Organizations That Design Environments: Lessons from Entrepreneurial Expertise," Organization Studies 29, no. 3 (March 1, 2008): 331-50, https://doi.org/10.1177/0170840607088017.

70 Jason E. Robbins, David M. Hilbert, and David F. Redmiles, "Extending Design Environments to Software Architecture Design,” Automated Software Engineering 5, no. 3 (July 1998): 261-90, https://doi.org/10.1023/A:1008652607643; Thomas Ludwig, Volkmar Pipek, and Peter Tolmie, "Designing for Collaborative Infrastructuring: Supporting Resonance Activities," Proceedings of the ACM on Human-Computer Interaction 2, no. CSCW (November 2018): 1-29, https://doi.org/10.1145/3274382; M. Cecília C. Baranauskas and Vania Paula de Almeida Neris, "Using Patterns to Support the Design of Flexible User Interaction," in HumanComputer Interaction. Interaction Design and Usability, ed. Julie A. Jacko, Lecture Notes in Computer Science (Berlin, Heidelberg: Springer, 2007), 1033-42, https://doi.org/10.1007/978-3-540-73105-4_113; Wendy E. Mackay, "Triggers and Barriers to Customizing Software," in Proceedings of the SIGCHI Conference on Human Factors in Computing Systems, CHI '91 (New York, NY, USA: Association for Computing Machinery, 1991), 153-60, https://doi.org/10.1145/108844.108867; Joanna McGrenere, Ronald M. Baecker, and Kellogg S. Booth, “A Field
} 
propose that work systems designed as flexible collaborative environments will be more likely to approach unity between work, worker, team, and organization.

Designing flexible environments requires more than technical acumen alone. Note that all 13 review articles appeared in management journals. ${ }^{71}$ Such reviews "highlight the need for theory and research to inform organizations in designing, structuring, and managing virtual teams." 72 This vantage point clarifies that while flexible collaborative environments will likely involve technology, managers play pivotal roles as environmental designers of tasks, team interactions, and (hopefully more inclusive) organizational cultures. Novel managerial designs should consider identities, incentives, information, and their interactions as organizations pursue productivity, innovation, and talent retention. But crucially, work design processes are more likely to create unity if they involve participatory co-creation with workers instead of merely for them. "Imposed" work designs are likely to foster dissent, ${ }^{73}$ unlike the unity derived from co-creation with employees. ${ }^{74}$ Consider how the increasing pervasiveness of "gig work" tends to achieve organizational flexibility, yet it comes at the expense of workers rather than by empowering workers to substantively co-create customized work environments that benefit everyone. ${ }^{75}$

To some extent, we already see organizations trending toward "unifying" environments with the adoption of products like Slack, Microsoft Teams, and GSuite which tout their abilities to streamline team processes through a central hub often located "in the cloud." But even purposebuilt platforms often fail to address objectives of unity. ${ }^{76}$ These largely normative platforms' singular and plural designs evidently yield mixed results and hence less unity, thereby sustaining a need for more flexible environments.

Given our review, designers and researchers can prioritize identifying means of constructing flexibility in terms of the themes we identify in Table 2 as a starting point. Take the intersection of communication, virtuality, and technology for example. Many of today's video technologies visually and auditorily place speakers and non-speakers in ways that prioritize extraversion $^{77}$ and likely yield Zoom fatigue. ${ }^{78}$ Some research explores constructing entirely

\footnotetext{
Evaluation of an Adaptable Two-Interface Design for Feature-Rich Software," ACM Transactions on ComputerHuman Interaction 14, no. 1 (May 2007): 3-es, https://doi.org/10.1145/1229855.1229858.

71 Thanks to an anonymous reviewer for this observation.

72 James H Dulebohn and Julia E Hoch, "Virtual Teams in Organizations," Human Resource Management Review 27, no. 4 (2017): 569, https://doi.org/10.1016/j.hrmr.2016.12.004.

73 cf. Thompson, "Time, Work-Discipline, and Industrial Capitalism."

${ }^{74}$ D'Ignazio and Klein, Data Feminism.

${ }^{75}$ Jeremias Prassl, Humans as a Service: The Promise and Perils of Work in the Gig Economy (Oxford University Press, 2018); M. Graham et al., "The Risks and Rewards of Online Gig Work at the Global Margins," 2017, https://ora.ox.ac.uk/objects/uuid:8c791d5a-e3a5-4a59-9b93-fbabea881554; Thomas Kohler et al., "Co-Creation in Virtual Worlds: The Design of the User Experience," MIS Quarterly 35, no. 3 (September 2011): 773-88, https://doi.org/10.2307/23042808.

76 cf. Kohli and Melville, "Digital Innovation."

${ }^{77}$ Much of face-to-face communication also favors extraversion, but abilities to move and choose who or what we focus on alleviate this some. Still, even face-to-face as constructed today can leave introverts with few comfortable ways to engage.

${ }^{78}$ Bailenson, "Nonverbal Overload."
} 
virtual three-dimensional environments as solutions, ${ }^{79}$ though these experiences remain bandwidth-intensive and buggy at present. ${ }^{80}$

Despite its relatively-low virtuality, even video communication involves numerous forms of "noise" that materially shape the symbolic meanings we glean from one another. Are there ways to use computer vision, audio processing, and natural language processing to build in additional flexibility for both collocated and remote workers? Videoconferencing software has already begun to address background noise in real time ${ }^{81}$ granting more flexibility to working parents with children at home, while live speech synthesis may provide transcription that facilitates greater accessibility; possibilities for overcoming audio and video garbling through reduced bandwidth requirements; for inferring employee satisfaction; and for collecting data that describes work patterns as social networks. These relatively novel forms of data collection could help managers identify network connections beneficial to individuals and teams as social network sites do, and perhaps new organizational structures.

A caution, though; that is not to say that any of these are necessarily "better." Materiality acknowledges trade-offs along with potential benefits, in this case including automating-away historically devalued actions like recordkeeping, increased computing needs, and privacy concerns. Nevertheless, by designing such work environments for flexible interaction - integrating symbols, objects, and actions-we may still provide workers with the customizability to experiment with solutions that appeal to their unique social, technical, and legal positionalities.

To be clear, this opportunity extends beyond recreating yesterday's work systems. Instead, designers will provide the greatest value by working interdisciplinarily with researchers and practitioners, managers and gig workers, to understand the underlying fundamental objectives of work and thinking broadly about how to achieve those objectives, from psychologically safe and inclusive cultures to innovation. ${ }^{82}$ Pandemic lockdowns exposed that many people missed the opportunity to build relationships with colleagues, develop shared culture, and find fundamental value in the depths and breadths of human connection afforded by the action of doing work with others. Incorporating the situated knowledge of individuals and collectives will prove necessary for our new work systems to stand the test of time. Better yet, it may capitalize on a plethora of novel hybrid capabilities toward greater flexibility for all.

Countless possibilities remain. In reading this piece, the reader may have recalled experiences of their own which went surprisingly poorly, or surprisingly well. Growing

\footnotetext{
${ }^{79}$ Kohler et al., "Co-Creation in Virtual Worlds"; Akshay Bhagwatwar, Anne Massey, and Alan Dennis, "Contextual Priming and the Design of 3D Virtual Environments to Improve Group Ideation," Information Systems Research 29, no. 1 (March 2018): 169-85, https://doi.org/10.1287/isre.2017.0721; Andreas Schmeil, Martin J. Eppler, and Sara de Freitas, "A Structured Approach for Designing Collaboration Experiences for Virtual Worlds," Journal of the Association for Information Systems 13, no. 10 (October 2012): 836-60.

${ }^{80} \mathrm{cf}$. Stacey Vanek Smith and Cardiff Garcia, "The Virtual Office," Podcast, The Indicator From Planet Money, March 31, 2021, https://www.npr.org/2021/03/31/983097569/the-virtual-office.

${ }^{81}$ Ron Amadeo, "Google Meet Takes on Zoom with AI-Powered Noise Cancellation," Ars Technica, June 9, 2020, https://arstechnica.com/gadgets/2020/06/google-meet-takes-on-zoom-with-ai-powered-noise-cancellation/.

${ }^{82}$ Markus Baer and Michael Frese, "Innovation Is Not Enough: Climates for Initiative and Psychological Safety, Process Innovations, and Firm Performance," Journal of Organizational Behavior 24, no. 1 (2003): 45-68, https://doi.org/10.1002/job.179; Nishii, "The Benefits of Climate for Inclusion for Gender-Diverse Groups."
} 
accustomed to the challenges of hybrid work does not innately justify its perpetuation. But with all of their liberations and frustrations, pandemic-necessitated changes generated many an impetus to develop prototypes of flexible environments for hybrid collaboration. Informed by the pandemic, from here on, we can proceed intentionally toward a thought of unity between heterogeneous work, workers, teams, organizations, and a more satisfying future for all.

\section{Funding}

This work is supported by Google Open Source under the Open Source Complex Ecosystems And Networks (OCEAN) project. Any opinions, findings, and conclusions or recommendations expressed in this material are those of the authors and do not necessarily reflect the views of Google Open Source. 